\title{
Smoking Cessation Carries a Short-Term Rising Risk for Newly Diagnosed Diabetes Mellitus Independently of Weight Gain: A 6-Year Retrospective Cohort Study
}

\author{
Yi-Ting Sung, ${ }^{1}$ Cheng-Ting Hsiao, ${ }^{2}$ I-Jen Chang, ${ }^{1}$ Yu-Chih Lin, ${ }^{1}$ and Chen-Yu Yueh ${ }^{1,3}$ \\ ${ }^{1}$ Department of Family Medicine, Chang Gung Memorial Hospital, Putz, Chiayi 613, Taiwan \\ ${ }^{2}$ Department of Emergency Medicine, Chang Gung Memorial Hospital, Putz, Chiayi 613, Taiwan \\ ${ }^{3}$ Chang Gung University of Science and Technology, Putz, Chiayi 613, Taiwan \\ Correspondence should be addressed to Chen-Yu Yueh; twohairs@cgmh.org.tw
}

Received 14 February 2016; Revised 17 May 2016; Accepted 9 June 2016

Academic Editor: Bernadette Bartlam

Copyright (C) 2016 Yi-Ting Sung et al. This is an open access article distributed under the Creative Commons Attribution License, which permits unrestricted use, distribution, and reproduction in any medium, provided the original work is properly cited.

\begin{abstract}
Background. The effects of smoking on human metabolism are complex. Although smoking increases risk for diabetes mellitus, smoking cessation was also reported to be associated with weight gain and incident diabetes mellitus. We therefore conducted this study to clarify the association between smoking status and newly diagnosed diabetes mellitus. Methods. An analysis was done using the data of a mass health examination performed annually in an industrial park from 2007 to 2013. The association between smoking status and newly diagnosed diabetes mellitus was analyzed with adjustment for weight gain and other potential confounders. Results. Compared with never-smokers, not only current smokers but also ex-smokers in their first two years of abstinence had higher odds ratios (ORs) for newly diagnosed diabetes mellitus (never-smokers 3.6\%, OR as 1; current smokers 5.5\%, OR = 1.499, 95\% CI = $1.147-1.960$, and $p=0.003$; ex-smokers in their first year of abstinence 7.5\%, OR $=1.829,95 \% \mathrm{CI}=0.906-3.694$, and $p=0.092$; and ex-smokers in their second year of abstinence $9.0 \%, \mathrm{OR}=2.020,95 \% \mathrm{CI}=1.031-3.955$, and $p=0.040$ ). Conclusion. Smoking cessation generally decreased risk for newly diagnosed diabetes mellitus. However, increased odds were seen within the first 2 years of abstinence independently of weight gain.
\end{abstract}

\section{Introduction}

Smoking is the leading avoidable cause of premature death [1-5]. Cessation of tobacco use undoubtedly benefits health. However, many studies have reported that smoking cessation may implicate some hazard effects on health. It may sometimes cause weight gain and result in obesity [6-13], the second important preventable risk for premature death [14]. It may also increase diabetes mellitus risk in the shortterm, presumptively owing to associated weight gain [13, $15]$. But there are controversies among studies regarding smoking cessation, weight gain, and risk of incident diabetes mellitus. Baum and Chou reported in their NBER study that smokers were $7.8 \%$ less likely to be obese. The declining use of cigarettes was the most significantly attributing factor for the soaring prevalence of obesity in USA [16]. The average weight gain after smoking cessation varied widely and was roughly estimated to be around 4-5 kg in two large-scale studies [12, 17], approximately equal to the amount different between the mean weight of smokers and nonsmokers. However, Weitzman et al. reported that environmental exposure to tobacco smoke or active smoking in American adolescents was associated with higher rate of metabolic syndrome and abdominal obesity [18]. In Williamson et al's national cohort study, people who never smoked and smokers weighed nearly the same at a 7 to 13 years' follow-up. Marked weight gain (i.e., greater than $13 \mathrm{~kg}$ ) may sometimes be strongly associated with smoking cessation, but it usually occurs in a minority of smoking quitters (i.e., in Williamson et al.s study, 9.8 percent of the men and 13.4 percent of the women who quit smoking) [12].

Additionally, there are debates about the risk for incident diabetes mellitus following smoking cessation, although the association between smoking and diabetes mellitus has been 
well established $[13,19-24]$. In this regard, Willi et al. did a meta-analysis on 25 prospective cohort studies including 1.2 million participants, with 45844 incidental cases of diabetes mellitus during a study follow-up period ranging from 5 to 30 years [19]. Compared with people who never smoked, the relative risk (RR) for diabetes mellitus in smokers was pooled and adjusted to be $1.44(95 \% \mathrm{CI}=1.31-1.58)$. The risk was highest in heavy smokers (more than 19 cigarettes a day; $\mathrm{RR}=1.61,95 \% \mathrm{CI}=1.43-1.80)$ and lower in former active smokers $(\mathrm{RR}=1.23,95 \% \mathrm{CI}=1.14-1.33)$, consistent with a dose-response phenomenon. However, several studies disclosed controversial results. In Nagaya et al.s longitudinal study, the risk for diabetes mellitus was increased by heavy smoking in obese men but decreased by light smoking in lean men [25]. On the other hand, study of Nakanishi et al. told another story. They found that smoking may dosedependently increase risk for incident diabetes mellitus. But the relative risk was stronger in men with lower body mass index (body mass index less than $24.2 \mathrm{~kg} / \mathrm{m}^{2}$ versus body mass index (BMI) of $24.2 \mathrm{~kg} / \mathrm{m}^{2}$ or more) [26]. Nevertheless, Oba et al. suggested that "smoking cessation increases shortterm risk of type 2 diabetes irrespective of weight gain" [27]. Likewise, Yeh et al's prospective cohort study found that the hazard for incident diabetes mellitus after smoking cessation reached its peak during the first 3 years (hazard ratio = $1.91 ; 95 \% \mathrm{CI}=1.19-3.05$ ) and then gradually decreased to 0 at 12 years [15]. Furthermore, Kamaura et al. reported that smoking cessation only raised the rate of BMI increase briefly. There was even no increase in incidence of impaired fasting glucose [28]. Importantly, a prospective cohort study using the data from the Framingham Offspring Study disclosed that the cardiovascular benefit of smoking cessation was weakened by the presence of diabetes mellitus. But it was not influenced by subsequent weight gain [29]. Therefore, the occurrence of diabetes mellitus rather than weight gain following smoking cessation is the critical issue for care providers to encourage their clients abstaining from smoking.

Taking all the above together, it is crucial to clarify whether smoking cessation may indeed bring individuals harmful metabolic effects (i.e., sustained overweight or obesity and incident diabetes mellitus) and identify individuals vulnerable to its adverse effects. In this regard, there are fairly few studies exploring smoking cessation, incident diabetes mellitus, and weight change together. We therefore conducted this study to examine the association between smoking cessation and incident diabetes mellitus and its correlation with weight gain.

\section{Materials and Methods}

This retrospective cohort study was done after being approved by Chang Gung Memorial Hospital Institutional Review Board (Document number IRB 102-1014B). The profiles for analysis were extracted from the mass health examination performed for employees in an industrial park in middle Taiwan annually from 2007 to 2013. Self-reported smoking status (including how long they have smoked or quitted smoking), drinking habit, and medical history (including diseases such as diabetes mellitus, hypertension, dyslipidemia, and viral hepatitis and medication currently prescribed) were recorded by standardized questionnaires and were reconfirmed by a nurse-administered check-up. A total of 11032 people were included for screening. The female employees (455 in number) were excluded because they counted less than $5 \%$ of the total number, and all did not smoke ever. To avoid complexity, people (2125 in number) who did not have complete data, smoked just socially or resumed smoking during the study period, or were diagnosed as DM at first examination were all excluded as well. There were 8452 male employees eventually included in this study. All the included individuals were categorized into never-smokers who had never smoked before, ex-smokers who had quitted smoking, and current smokers who had been smoking until the final health examination. The ex-smokers were further divided by the number of years they had quitted smoking. The odds ratios (ORs) for newly diagnosed diabetes mellitus were then calculated with adjustment for potential confounders and compared among groups.

2.1. Laboratory Measurement. All biochemical tests were performed with fresh samples as instructed by manufacturer (7600 Clinical Analyzer, Hitachi High-Tech, Tokyo, Japan) under standardized quality control in the Clinical Laboratory Department at Chang Gung Memorial Hospital at Chiayi, Taiwan.

\subsection{Definition of Diabetes Mellitus and Newly Diagnosed Dia-} betes Mellitus. The confirmation of diabetes mellitus usually needs two separated occasions of elevated plasma glucose higher than $6.9 \mathrm{mmol} / \mathrm{L}(125 \mathrm{mg} / \mathrm{dL})$ or even strictly meeting the requirement of standard oral glucose tolerance test. In this retrospective study, it is hard to use these criteria. To avoid missing potential cases, people without history of diabetes mellitus but with just one occasion of fasting plasma glucose higher than $6.9 \mathrm{mmol} / \mathrm{L}(125 \mathrm{mg} / \mathrm{dL})$ or newly receiving drug therapy for hyperglycemia were regarded as newly diagnosed diabetes mellitus.

2.3. Definition of Other Variables in the Analysis. The status of alcohol consumption was categorized as "drinks often," "drinks occasionally," and "drinks seldom." People who just drank less than twice a month were regarded as "drinks occasionally." Those who drank twice a month or more frequently were regarded as "drinks often." Man with waist circumference $90 \mathrm{~cm}$ or higher was regarded as abdominal obesity. Systolic blood pressure equal to or higher than $130 \mathrm{mmHg}$, or diastolic blood pressure equal to or higher than $85 \mathrm{mmHg}$, or current use of antihypertensive medicines was regarded as high blood pressure. Serum triglyceride equal to or higher than $1.7 \mathrm{mmol} / \mathrm{L}(150 \mathrm{mg} / \mathrm{dL})$ was regarded as dyslipidemia. Fasting plasma glucose from 5.6 to $6.9 \mathrm{mmol} / \mathrm{L}$ (100 to $125 \mathrm{mg} / \mathrm{dL}$ ) was regarded as impaired fasting glucose.

2.4. Statistical Analysis. Logistic regression in SPSS 18.0 for Windows (SPSS Inc., Chicago, IL, USA) was used to estimate the ORs for newly diagnosed diabetes mellitus with smoking status as the main independent variable. The analysis was performed with adjustment for potential confounders including 


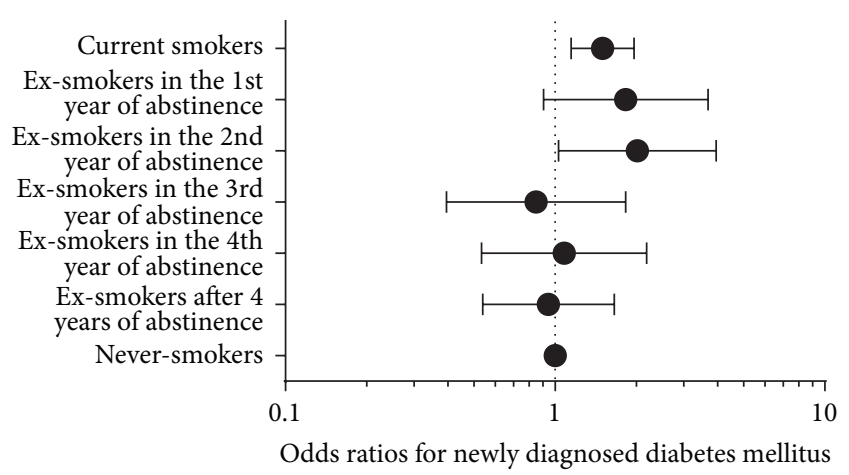

FIgURE 1: The comparison of the odds ratios for the incidence of newly diagnosed diabetes mellitus by smoking status. With never-smokers as reference $(\mathrm{OR}=1)$, current smokers and exsmokers in the first and second year of abstinence were inclined to have newly diagnosed diabetes mellitus, though the increased odds ratio for ex-smokers in the first year of abstinence was not statistically significant. All odds ratios were adjusted for age, alcohol consumption, abdominal obesity, high BP, dyslipidemia and impaired fasting glucose at their first examination, and weight gain between the first and the final examination.

age, status of alcohol consumption, abdominal obesity, high blood pressure, dyslipidemia and impaired fasting glucose at the first examination, and weight gain between the first and the final examination. A $p$ value less than 0.05 and a 95\% confidence interval (CI) of OR not containing 1 were considered statistically significant. The numbers of mean are presented with standard deviations in parenthesis.

\section{Results}

The study included 8452 men aged, at their first health examination, from 24 to 70 with mean age $41.4( \pm 7.1)$ years. There were 4370 (51.7\%) men who never smoked, 1169 (13.7\%) men who had quitted smoking, and 2913 (34.5\%) men who kept on smoking. In the group that had quitted smoking, there were $146(1.7 \%)$ men within the first year of smoking cessation, $144(1.7 \%)$ within the $2 \mathrm{nd}, 278$ (3.3\%) within the $3 \mathrm{rd}$, and $202(2.4 \%)$ within the 4th and 399 (4.7\%) had quitted smoking longer than 4 years. The characteristics of the grouped individuals by smoking status were summarized in Table 1.

During this 6-year period, 374 men (4.4\%) were newly diagnosed as diabetes mellitus. Compared with neversmokers, the current smokers had higher odds to have newly diagnosed diabetes mellitus (as shown in Figure 1). Additionally, the ex-smokers within their first 2 years of abstinence were also inclined to have newly diagnosed diabetes mellitus (never-smokers 3.6\%, OR as 1; current smokers 5.5\%, OR $=1.499,95 \% \mathrm{CI}=1.147-1.960$, and $p=0.003$; ex-smokers in the first year of abstinence $7.5 \%$, OR $=1.829,95 \% \mathrm{CI}=$ $0.906-3.694$, and $p=0.092$; ex-smokers in the second year of abstinence $9.0 \%, \mathrm{OR}=2.020,95 \% \mathrm{CI}=1.031-3.955$, and $p=0.040$; ex-smokers in the third year of abstinence $2.9 \%$, $\mathrm{OR}=0.850,95 \% \mathrm{CI}=0.396-1.826$, and $p=0.677$; ex-smokers in the fourth year of abstinence $5.0 \%, \mathrm{OR}=1.080,95 \% \mathrm{CI}=$
$0.533-2.187$, and $p=0.831$; and the ex-smokers after 4 years of smoking cessation $4.0 \%, \mathrm{OR}=0.945,95 \% \mathrm{CI}=0.539-1.658$, and $p=0.845)$.

\section{Discussion}

Tobacco smoking is a well established risk factor for many diseases, including several kinds of cancer [30-32] and cardiovascular and lung diseases. It raises the death rate in middle age by twofold to threefold $[2,4]$. In particular, it may predispose to or is associated with type 2 diabetes mellitus $[13,19-25,27,33-36]$, which further contributes to the risk of cardiovascular diseases [37]. However, there are controversies about metabolic benefits from smoking cessation. In terms of smoking cessation, weight gain, and diabetes mellitus, many studies disclose that smoking and excess weight are often inversely related. However, this association seems to interact significantly with age. In MacKay et al's study, never-smokers or ex-smokers aged 16-24 years were not more likely to be overweight or obese than active smokers of the same age [11]. Although smoking cessation could be accompanied with a weight gain, most of it occurs during the first 6 months [38]. The usual average weight gain is around $4-5 \mathrm{~kg}$. People at younger age (e.g., $<55$ years) and lower socioeconomic status and who used to smoke heavily (e.g., more than 25 cigarettes per day) or have history of binge eating are at risk for marked weight gain (i.e., more than $10 \mathrm{~kg}$ ) [12,39]. Moreover, in Clair et al.s study, weight gain following smoking cessation did not influence its cardiovascular benefit unless there was a coexisting diabetes mellitus [29]. Even in patients with diabetes mellitus, smoking cessation may still reduce risk of premature death although it usually takes several years for effect [40]. It then becomes crucial to determine whether smoking cessation per se would increase risk for incidental diabetes mellitus despite weight gain or not.

In our study, we found that ex-smokers during their first two years of abstinence have even higher odds than current smokers for newly diagnosed diabetes mellitus, though the increased odds ratio for ex-smokers in the first year of abstinence was not statistically significant (as shown in Figure 1). This tendency is independent of weight gain. It seems incredulous that people should immediately face rising odds for incident diabetes mellitus when they start quitting smoking. This contradictory result may arise from the immediate withdrawal of beneficial metabolic effect of certain constituents (e.g., nicotine) in tobacco [41-45] and the delayed subsiding of adverse effects or irreversible harmful effects from smoking $[46,47]$. Like some diet drugs (e.g., sibutramine, phentermine, and buspirone), nicotine may suppress appetite and prevent weight gain by increasing central nervous system levels of norepinephrine, dopamine, and serotonin [48]. Smoking may influence appetite partially through the activation of hypothalamic melanocortin system [49]. It may also promote release of catecholamines and cortisol and suppress adiponectin [50,51]. Moreover, the exposure to nicotine may increase beta cell apoptosis [52]. Although smoking is generally implicated with harmful effects, there are several studies that disclosed beneficial metabolic effects from certain constituents of tobacco [42-45]. Complexity of 


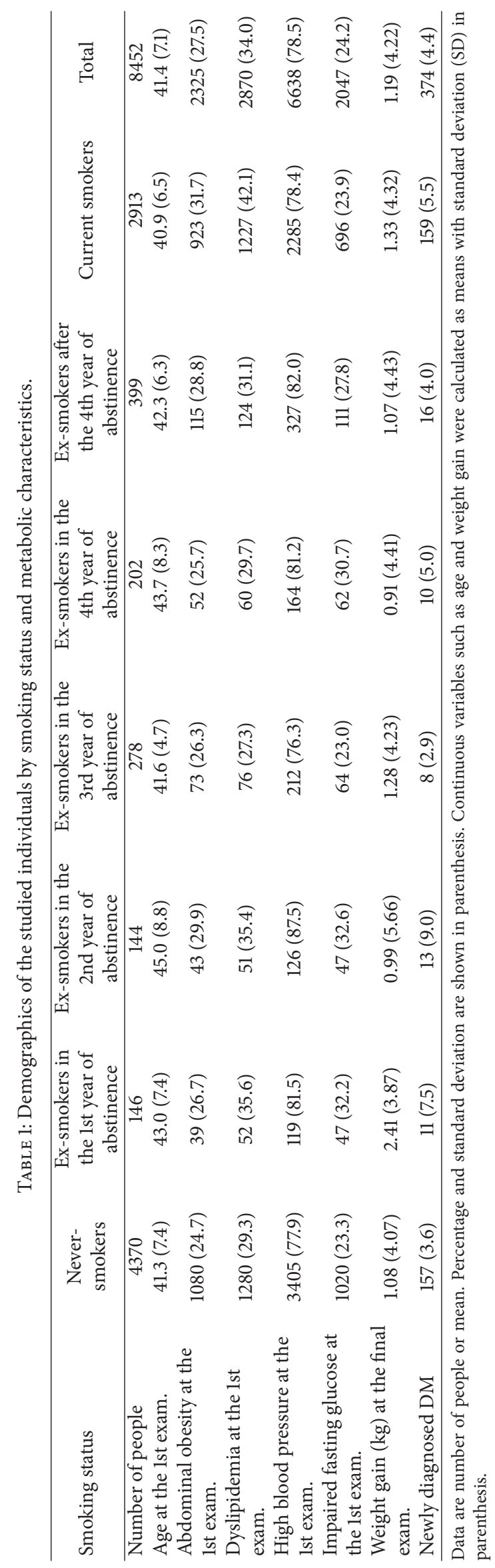


all the above findings could partially explain why smokers are prone to develop insulin resistance and have higher cardiovascular risk and the controversy why smoking cessation may sometimes not only cause weight gain $[9,53]$ but also increase incidence of diabetes mellitus [27, 28, 54].

There are a number of limitations in our study. The reasons people quitted smoking could not be explored. In particular, some of the ex-smokers might quit smoking because of great ill health. It may make us overestimate the smoking associated risk for incident diabetes mellitus. Additionally, the smoking status could not be further categorized by quantity of exposure. Given that smoking may reflect a clustering of risky life styles, there should be quite a few residual confounders in this study. In particular, diagnostic bias defining diabetes mellitus by only one occasion of abnormal fasting glucose, monogender, and the lack of counting the quantity of cigarette smoking all make the results of our study biased and of limitation. However, it may still provide some useful information. It discloses that smoking cessation generally decreases risk for incidental diabetes mellitus. But it may meanwhile carry a short-term (i.e., within the first couple of years) rising risk for incident diabetes mellitus. This association is independent of weight change.

\section{Conclusion}

Smoking cessation generally tends to decrease the incidence of newly diagnosed diabetes mellitus. However, rising odds are seen in the first 2 years after quitting smoking in our study. In particular, it is independent of weight gain. Therefore, we suggest that intensified modification of life style or other strategies for prevention of diabetes mellitus may be needed before and immediately after smoking cessation. At least, for smokers and ex-smokers at risk for diabetes mellitus, monitoring at shorter intervals should be considered for early detection.

\section{Competing Interests}

The authors declare that there is no conflict of interests regarding the publication of this paper.

\section{Acknowledgments}

This work was supported by the internal grants of Chang Gung Memorial Hospital (Grants nos. CMRPG6B0291, CMRPG6B0292, and CMRPG6B0293).

\section{References}

[1] P. Jha, R. Peto, W. Zatonski, J. Boreham, M. J. Jarvis, and A. D. Lopez, "Social inequalities in male mortality, and in male mortality from smoking: indirect estimation from national death rates in England and Wales, Poland, and North America," The Lancet, vol. 368, no. 9533, pp. 367-370, 2006.

[2] S. E. Vollset, A. Tverdal, and H. K. Gjessing, "Smoking and deaths between 40 and 70 years of age in women and men," Annals of Internal Medicine, vol. 144, no. 6, pp. 381-389, 2006.

[3] P. Jha, B. Jacob, V. Gajalakshmi et al., "A nationally representative case-control study of smoking and death in India," New
England Journal of Medicine, vol. 358, no. 11, pp. 1137-1147, 2008.

[4] I. T. Gram, S. Sandin, T. Braaten, E. Lund, and E. Weiderpass, "The hazards of death by smoking in middle-aged women," European Journal of Epidemiology, vol. 28, no. 10, pp. 799-806, 2013.

[5] J. Maag, J. Braun, M. Bopp, and D. Faeh, "Direct estimation of death attributable to smoking in Switzerland based on record linkage of routine and observational data," Nicotine and Tobacco Research, vol. 15, no. 9, pp. 1588-1597, 2013.

[6] J. Brožek and A. Keys, "Changes of body weight in normal men who stop smoking cigarettes," Science, vol. 125, no. 3259, article 1203, 1957.

[7] R. W. Howell, "Obesity and smoking habits," British Medical Journal, vol. 4, no. 787, p. 625, 1971.

[8] G. W. Comstock and R. W. Stone, "Changes in body weight and subcutaneous fatness related to smoking habits," Archives of Environmental Health, vol. 24, no. 4, pp. 271-276, 1972.

[9] P. H. Blitzer, A. A. Rimm, and E. E. Giefer, "The effect of cessation of smoking on body weight in 57,032 women: cross-sectional and longitudinal analyses," Journal of Chronic Diseases, vol. 30, no. 7, pp. 415-429, 1977.

[10] K. Patel, M. K. Hargreaves, J. Liu et al., "Relationship between smoking and obesity among women," American Journal of Health Behavior, vol. 35, no. 5, pp. 627-636, 2011.

[11] D. F. MacKay, L. Gray, and J. P. Pell, "Impact of smoking and smoking cessation on overweight and obesity: scotlandwide, cross-sectional study on 40,036 participants," BMC Public Health, vol. 13, article 348, 2013.

[12] D. F. Williamson, J. Madans, R. F. Anda, J. C. Kleinman, G. A. Giovino, and T. Byers, "Smoking cessation and severity of weight gain in a national cohort," The New England Journal of Medicine, vol. 324, no. 11, pp. 739-745, 1991.

[13] S. G. Wannamethee, A. G. Shaper, and I. J. Perry, "Smoking as a modifiable risk factor for type 2 diabetes in middle-aged men," Diabetes Care, vol. 24, no. 9, pp. 1590-1595, 2001.

[14] C. H. Hennekens and F. Andreotti, "Leading avoidable cause of premature deaths worldwide: case for obesity," American Journal of Medicine, vol. 126, no. 2, pp. 97-98, 2013.

[15] H.-C. Yeh, B. B. Duncan, M. I. Schmidt, N.-Y. Wang, and F. L. Brancati, "Smoking, smoking cessation, and risk for type 2 diabetes mellitus: a cohort study," Annals of Internal Medicine, vol. 152, no. 1, pp. 10-17, 2010.

[16] C. L. Baum and S.-Y. Chou, "The socio-economic causes of obesity," National Bureau of Economic Research Working Paper 17423, 2011.

[17] J. T. Wack and J. Rodin, "Smoking and its effects on body weight and the systems of caloric regulation," American Journal of Clinical Nutrition, vol. 35, no. 2, pp. 366-380, 1982.

[18] M. Weitzman, S. Cook, P. Auinger et al., "Tobacco smoke exposure is associated with the metabolic syndrome in adolescents," Circulation, vol. 112, no. 6, pp. 862-869, 2005.

[19] C. Willi, P. Bodenmann, W. A. Ghali, P. D. Faris, and J. Cornuz, "Active smoking and the risk of type 2 diabetes: a systematic review and meta-analysis," The Journal of the American Medical Association, vol. 298, no. 22, pp. 2654-2664, 2007.

[20] Y. Hayashino, S. Fukuhara, T. Okamura et al., "A prospective study of passive smoking and risk of diabetes in a cohort of workers: the High-Risk and Population Strategy for Occupational Health Promotion (HIPOP-OHP) study," Diabetes Care, vol. 31, no. 4, pp. 732-734, 2008. 
[21] S. H. Jee, A. W. Foong, N. W. Hur, and J. M. Samet, "Smoking and risk for diabetes incidence and mortality in Korean men and women," Diabetes Care, vol. 33, no. 12, pp. 2567-2572, 2010.

[22] B. Kowall, W. Rathmann, K. Strassburger et al., "Association of passive and active smoking with incident type 2 diabetes mellitus in the elderly population: the KORA S4/F4 cohort study," European Journal of Epidemiology, vol. 25, no. 6, pp. 393402, 2010.

[23] L. Radzevičiene and R. Ostrauskas, "Smoking habits and the risk of type 2 diabetes: a case-control study," Diabetes and Metabolism, vol. 35, no. 3, pp. 192-197, 2009.

[24] L. Zhang, G. C. Curhan, F. B. Hu, E. B. Rimm, and J. P. Forman, "Association between passive and active smoking and incident type 2 diabetes in women," Diabetes Care, vol. 34, no. 4, pp. 892897, 2011.

[25] T. Nagaya, H. Yoshida, H. Takahashi, and M. Kawai, "Heavy smoking raises risk for type 2 diabetes mellitus in obese men; but, light smoking reduces the risk in lean men: a follow-up study in Japan," Annals of Epidemiology, vol. 18, no. 2, pp. 113118, 2008.

[26] N. Nakanishi, K. Nakamura, Y. Matsuo, K. Suzuki, and K. Tatara, "Cigarette smoking and risk for impaired fasting glucose and type 2 diabetes in middle-aged Japanese men," Annals of Internal Medicine, vol. 133, no. 3, pp. 183-191, 2000.

[27] S. Oba, M. Noda, K. Waki et al., "Smoking cessation increases short-term risk of type 2 diabetes irrespective of weight gain: the Japan Public Health Center-Based Prospective Study," PLoS ONE, vol. 7, no. 2, Article ID el7061, 2012.

[28] M. Kamaura, H. Fujii, S. Mizushima, and O. Tochikubo, "Weight gain and risk of impaired fasting glucose after smoking cessation," Journal of Epidemiology, vol. 21, no. 6, pp. 431-439, 2011.

[29] C. Clair, N. A. Rigotti, B. Porneala et al., "Association of smoking cessation and weight change with cardiovascular disease among adults with and without diabetes," The Journal of the American Medical Association, vol. 309, no. 10, pp. 1014-1021, 2013.

[30] B. Ehdaie, H. Furberg, E. C. Zabor et al., "Impact of smoking status at diagnosis on disease recurrence and death in upper tract urothelial carcinoma," BJU International, vol. 111, no. 4, pp. 589-595, 2013.

[31] A. Gawron, L. Hou, H. Ning, J. D. Berry, and D. M. Lloyd-Jones, "Lifetime risk for cancer death by sex and smoking status: the lifetime risk pooling project," Cancer Causes and Control, vol. 23, no. 10, pp. 1729-1737, 2012.

[32] Y. Lin, K. Yagyu, J. Ueda, M. Kurosawa, A. Tamakoshi, and S. Kikuchi, "Active and passive smoking and risk of death from pancreatic cancer: findings from the Japan collaborative cohort study," Pancreatology, vol. 13, no. 3, pp. 279-284, 2013.

[33] F. S. Facchini, C. B. Hollenbeck, J. Jeppesen, Y.-D. Ida Chen, and G. M. Reaven, "Insulin resistance and cigarette smoking," The Lancet, vol. 339, no. 8802, pp. 1128-1130, 1992.

[34] S. Carlsson, K. Midthjell, and V. Grill, "Smoking is associated with an increased risk of type 2 diabetes but a decreased risk of autoimmune diabetes in adults: an 11-year follow-up of incidence of diabetes in the Nord-Trøndelag study," Diabetologia, vol. 47, no. 11, pp. 1953-1956, 2004.

[35] N. H. Cho, J. C. N. Chan, H. C. Jang, S. Lim, H. L. Kim, and S. H. Choi, "Cigarette smoking is an independent risk factor for type 2 diabetes: a four-year community-based prospective study," Clinical Endocrinology, vol. 71, no. 5, pp. 679-685, 2009.

[36] M. W. Cullen, J. O. Ebbert, R. A. Vierkant, A. H. Wang, and J. R. Cerhan, "No interaction of body mass index and smoking on diabetes mellitus risk in elderly women," Preventive Medicine, vol. 48, no. 1, pp. 74-78, 2009.

[37] R. H. Fagard, "Smoking amplifies cardiovascular risk in patients with hypertension and diabetes," Diabetes Care, vol. 32, supplement 2, pp. S429-S431, 2009.

[38] R. C. Klesges, S. E. Winders, A. W. Meyers et al., "How much weight gain occurs following smoking cessation? A comparison of weight gain using both continuous and point prevalence abstinence," Journal of Consulting and Clinical Psychology, vol. 65, no. 2, pp. 286-291, 1997.

[39] C. Filozof, M. C. Fernández Pinilla, and A. Fernández-Cruz, "Smoking cessation and weight gain," Obesity Reviews, vol. 5, no. 2, pp. 95-103, 2004.

[40] N. Chaturvedi, L. Stevens, and J. H. Fuller, "Which features of smoking determine mortality risk in former cigarette smokers with diabetes? The World Health Organization Multinational Study Group," Diabetes Care, vol. 20, no. 8, pp. 1266-1272, 1997.

[41] S. E. Kahn, J. C. Beard, M. W. Schwartz et al., "Increased $\beta$-cell secretory capacity as mechanism for islet adaptation to nicotinic acid-induced insulin resistance," Diabetes, vol. 38, no. 5, pp. 562-568, 1989.

[42] T.-Y. Xu, L.-L. Guo, P. Wang et al., "Chronic exposure to nicotine enhances insulin sensitivity through $\alpha 7$ nicotinic acetylcholine receptor-STAT3 pathway," PLoS ONE, vol. 7, no. 12, Article ID e51217, 2012.

[43] J. G. Mabley, P. Pacher, G. J. Southan, A. L. Salzman, and C. Szabó, "Nicotine reduces the incidence of type I diabetes in mice," Journal of Pharmacology and Experimental Therapeutics, vol. 300, no. 3, pp. 876-881, 2002.

[44] R.-H. Liu, M. Mizuta, and S. Matsukura, "Long-term oral nicotine administration reduces insulin resistance in obese rats," European Journal of Pharmacology, vol. 458, no. 1-2, pp. 227-234, 2003.

[45] R.-H. Liu, M. Mizuta, and S. Matsukura, "The expression and functional role of nicotinic acetylcholine receptors in rat adipocytes," Journal of Pharmacology and Experimental Therapeutics, vol. 310, no. 1, pp. 52-58, 2004.

[46] T. Axelsson, P.-A. Jansson, U. Smith, and B. Eliasson, "Nicotine infusion acutely impairs insulin sensitivity in type 2 diabetic patients but not in healthy subjects," Journal of Internal Medicine, vol. 249, no. 6, pp. 539-544, 2001.

[47] T. M. Morgan, L. Crawford, A. Stoller, D. Toth, K. T. Yeo, and J. A. Baron, "Acute effects of nicotine on serum glucose insulin growth hormone and cortisol in healthy smokers," Metabolism, vol. 53, no. 5, pp. 578-582, 2004.

[48] L. L. Ioannides-Demos, L. Piccenna, and J. J. McNeil, "Pharmacotherapies for obesity: past, current, and future therapies," Journal of Obesity, vol. 2011, Article ID 179674, 18 pages, 2011.

[49] Y. S. Mineur, A. Abizaid, Y. Rao et al., "Nicotine decreases food intake through activation of POMC neurons," Science, vol. 332, no. 6035, pp. 1330-1332, 2011.

[50] N. L. Benowitz, "Cigarette smoking and cardiovascular disease: pathophysiology and implications for treatment," Progress in Cardiovascular Diseases, vol. 46, no. 1, pp. 91-111, 2003.

[51] T. Miyazaki, K. Shimada, H. Mokuno, and H. Daida, "Adipocyte derived plasma protein, adiponectin, is associated with smoking status in patients with coronary artery disease," Heart, vol. 89, no. 6, pp. 663-664, 2003.

[52] A. C. Holloway, G. E. Lim, J. J. Petrik, W. G. Foster, K. M. Morrison, and H. C. Gerstein, "Fetal and neonatal exposure to nicotine in Wistar rats results in increased beta cell apoptosis at 
birth and postnatal endocrine and metabolic changes associated with type 2 diabetes," Diabetologia, vol. 48, no. 12, pp. 26612666, 2005.

[53] T. Gordon, W. B. Kannel, T. R. Dawber, and D. McGee, "Changes associated with quitting cigarette smoking: the Framingham study," American Heart Journal, vol. 90, no. 3, pp. 322-328, 1975.

[54] J. Luo, J. Rossouw, E. Tong et al., "Smoking and diabetes: does the increased risk ever go away?" American Journal of Epidemiology, vol. 178, no. 6, pp. 937-945, 2013. 


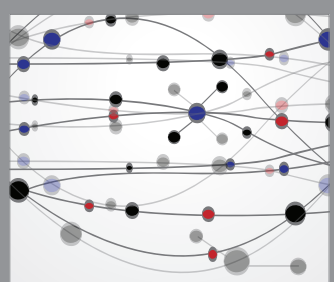

The Scientific World Journal
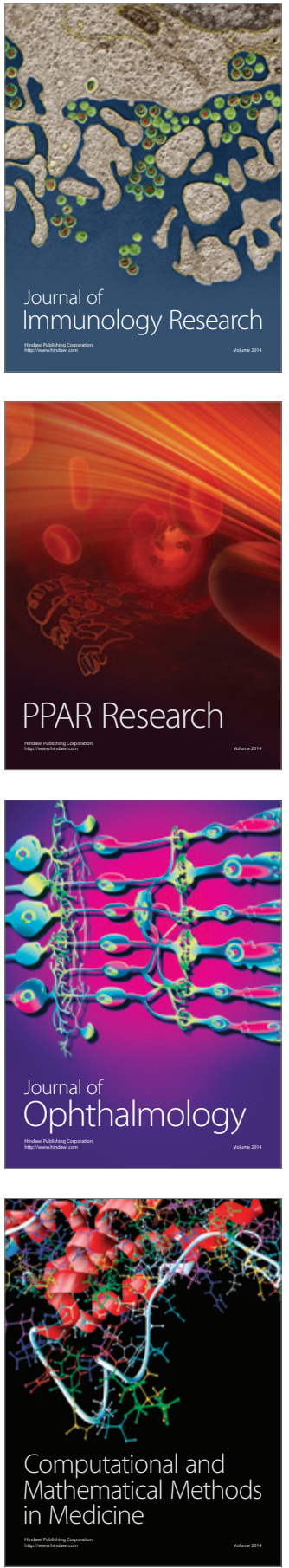

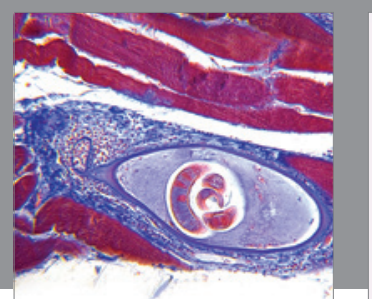

Gastroenterology Research and Practice

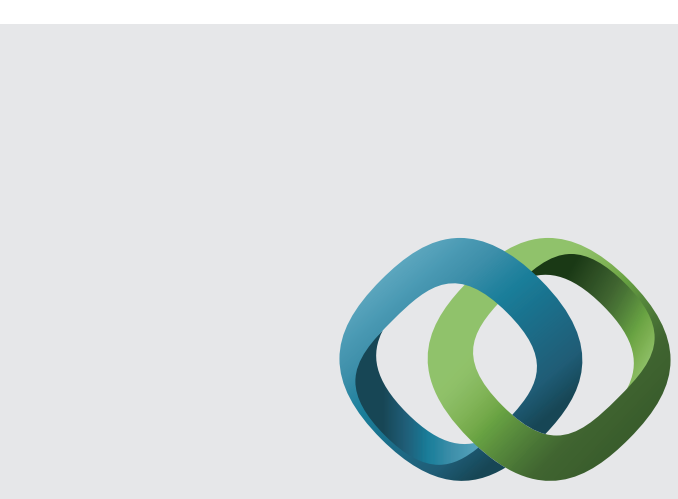

\section{Hindawi}

Submit your manuscripts at

http://www.hindawi.com
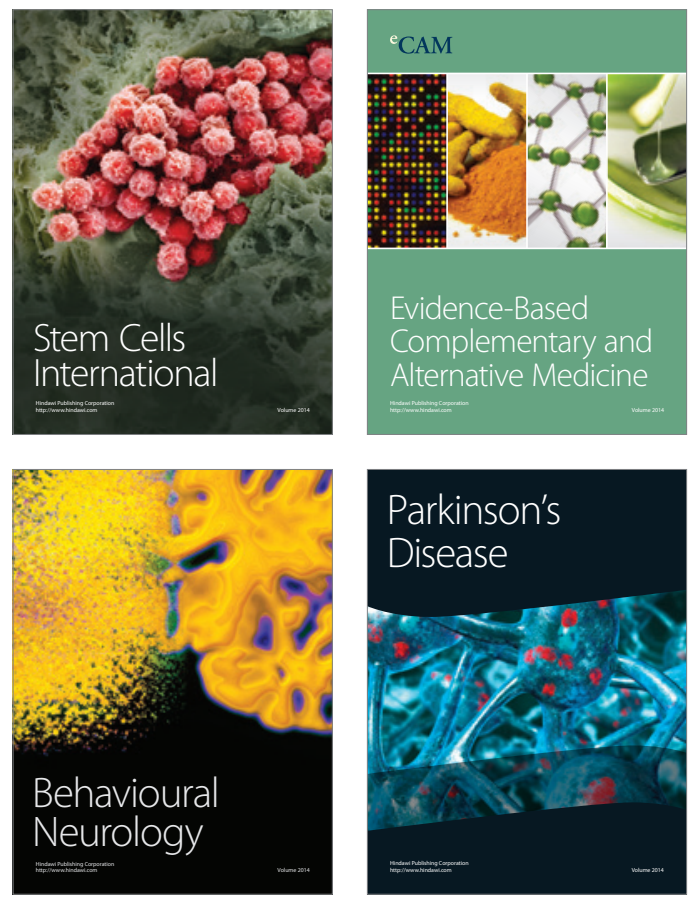
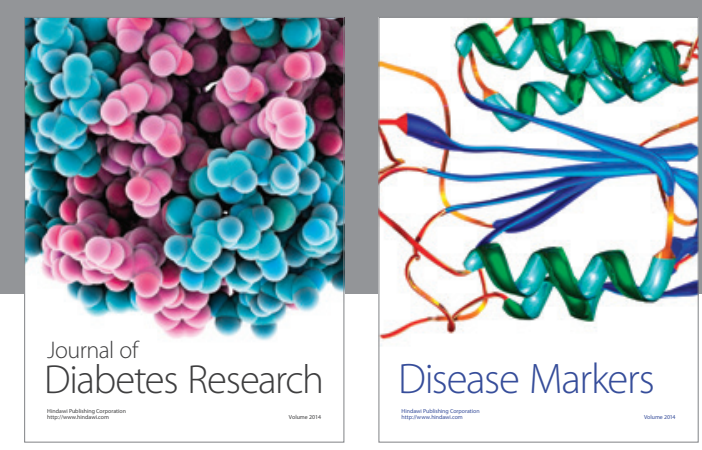

Disease Markers
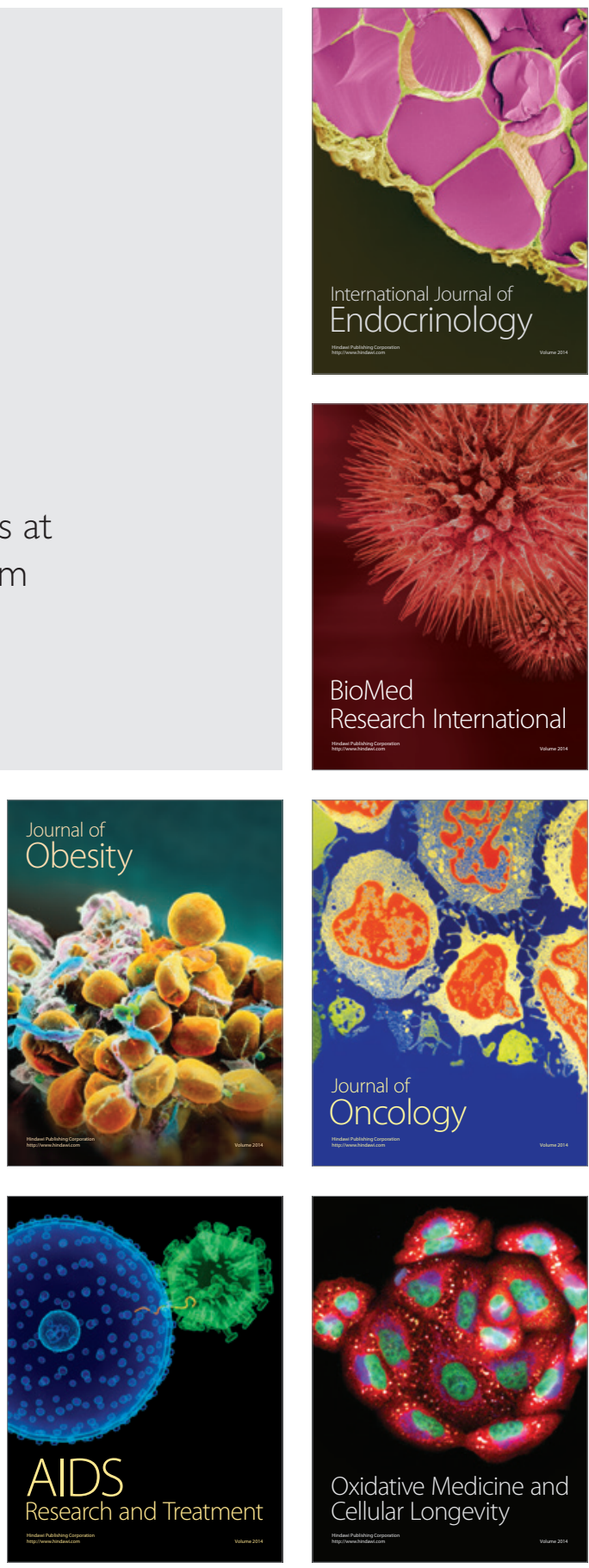